\title{
Prenatal Exposure to IL-1 $\beta$ Results in Disturbed Skeletal Growth in Adult Rat Offspring
}

\author{
DIANA SWOLIN-EIDE, CECILIA NILSSON, AGNETA HOLMÄNG, AND CLAES OHLSSON \\ Center of Bone Research at the Sahlgrenska Academy, RCEM, Department of Internal Medicine [D.S.-E., \\ C.O.J, Göteborg Pediatric Growth Research Center, Institute for the Health of Women and Children, \\ Queen Silvia Children's Hospital [D.S.-E.], and Wallenberg Laboratory [C.N., A.H.], Sahlgrenska \\ University Hospital, S-413 45 Göteborg, Sweden
}

\begin{abstract}
Events occurring early in life or prenatally are able to play important roles in the pathogenesis of diseases in adult life. Different sorts of stress or hormonal influences, during particular periods of pregnancy, may result in persistent or transient changes in physiology. IL-1 is a multifunctional cytokine that is involved in bone metabolism. The aim of the present study was to investigate whether exposure to IL- $1 \beta$ during fetal life has any effect on skeletal growth or bone mineral density in adult rat offspring. Pregnant rats were given intraperitoneal injections of IL- $1 \beta, 1 \mu \mathrm{g} / \mathrm{rat}$, or saline on days 8,10 , and 12 of gestation. Male IL-1-exposed offspring showed reduced height, areal bone mineral density, and bone mineral content at vertebra L5. Tibial length was reduced in both male and female offspring. Peripheral quantitative computed tomography analyses revealed reduced cortical bone mineral content caused by a decreased cortical cross-sectional area as a result of a decreased cortical thickness,
\end{abstract}

ABSTRACT

whereas there was no reduction in the amount of trabecular bone in the tibia of male offspring. Our results demonstrate that prenatal exposure to IL-1 can induce specific programming of skeletal tissue. In conclusion, prenatal IL-1 exposure results in decreased skeletal growth and a reduced amount of cortical bone but unchanged trabecular bone mineral density in adult rat offspring. (Pediatr Res 55: 598-603, 2004)
Abbreviations
DXA, dual-energy x-ray absorptiometry
BMC, bone mineral content
BMD, bone mineral density
pQCT, peripheral quantitative computed tomography
HPA, hypothalamic-pituitary-adrenal
TRAP 5b, tartrate-resistant acid phosphatase $5 \mathrm{~b}$

It has been shown that events occurring early in life or prenatally are able to play important roles in the pathogenesis of adult diseases in both humans and animals $(1,2)$. The process whereby a stimulus or insult at a sensitive or critical period of development has long-term effects is termed programming (3). A low birth weight and leanness at birth have been shown to be associated with insulin resistance in children and adolescents $(4,5)$. Furthermore, a recent clinical study

Received January 16, 2003; accepted August 28, 2003.

Correspondence: Diana Swolin-Eide M.D., Ph.D., Department of Pediatrics, Queen Silvia Children's Hospital, Sahlgrenska University Hospital/ÖS, S-416 85 Göteborg, Sweden; e-mail: diana.swolin@medic.gu.se

Supported by grants from the Swedish Foundation for Strategic Research, Lundberg Foundation, the Torsten and Ragnar Söderbergs Foundation, the Emil and Vera Cornell Foundation, Petrus and Augusta Hedlunds Foundation, the Swedish Cancer Fund, the Novo Nordisk Foundation, Magnus Bergvalls Foundation, The Swedish Medical Research Council (Project No. 12206, 7509), the Swedish Heart and Lung Foundation, the Wilhelm and Martina Lundgrens Foundation, the Åke Wibergs Foundation, The Göteborgs Läkaresällskap, the Svenska Läkaresällskapet Foundation, the Sahlgrenska University Foundation, the Göteborg Children's Hospital Research Foundation, the Tore Nilssons Foundation, SWEGENE Center for Bio-Imaging, Gothenburg University, and The Royal Society of Arts and Sciences in Göteborg.

DOI: 10.1203/01.PDR.0000112103.95738.25 suggests that a low birth weight is associated with lower adult bone and muscle mass, indicating that the risk of osteoporosis in later life might be programmed by genetic or environmental influences during gestation (6).

IL-1 is a multifunctional cytokine that is involved in the regulation of bone metabolism, hematopoiesis, and inflammatory responses (7). Maternal infection during pregnancy leads to a systemic inflammatory response, with release of cytokines and glucocorticoids, representing a stressful event for the fetus. Early onset of neonatal sepsis is associated with increased IL-1 levels in umbilical plasma (8). Lipopolysaccharides from bacteria have been shown, via the release of IL-1, IL-6, and tumor necrosis factor- $\alpha$, to regulate the neuroendocrine axis in adult rats and humans (9-11). Prenatal treatment with IL-1 results in long-lasting alterations in psychomotor development, behavior, and the neuroendocrine system $(12,13)$.

IL-1 is also regarded as a bone-regulating cytokine. It is involved in the regulation of bone remodeling (7, 14-16), fracture healing (17), inflammatory bone diseases (18), and malignant bone destruction (19). IL-1 is a potent stimulator of osteoclast formation, associated with increased bone resorption 
$(14,19,20)$. Both IL- $1 \alpha$ and IL- $1 \beta$ are produced by osteoblasts $(21,22)$, and IL-1 stimulates the proliferation of cultured osteoblasts (23). Thus the major effect of IL-1 on bone metabolism is to regulate bone resorption, but an effect on bone formation cannot be excluded.

The aim of the present study was to investigate whether prenatal IL-1 exposure affects skeletal growth or mineralization of bones in rat offspring.

\section{METHODS}

Animals. Timed-pregnant nulliparous Wistar rats (B\&K Universal, Sollentuna, Sweden) were housed, one animal to a cage, until parturition. Pups were raised with a lactating mother until $4 \mathrm{wk}$ of age. Thereafter, they lived in cages, with three to four animals from the same group per cage. The study was approved by the Animal Ethic Committee of Göteborg University. Rats were housed under controlled conditions, at a temperature of $21^{\circ}-22^{\circ} \mathrm{C}$, humidity of 55 to $65 \%$, and light on from 0500 to $1900 \mathrm{~h}$. They received a commercial rat chow [containing $18.7 \%$ protein, $4.7 \%$ fat, and $63 \%$ carbohydrates with sufficient supply of vitamins and minerals (B\&K Universal)]. Tap water was available ad libitum.

Dams and litters. Dams were randomly divided and given i.p. injections of IL-1 $\beta$ (1 $\mu \mathrm{g} / \mathrm{rat}$; Boehringer Mannheim Biochemica, Mannheim, Germany) on days 8, 10, and 12 of gestation $(n=7)$. Control dams $(n=7)$ were injected i.p. with physiologic saline. The IL-1 $\beta$ dose $(1 \mu \mathrm{g} / \mathrm{rat})$ was chosen as it is known to stimulate the HPA axis in the adult rat (24). It is also known to result in no fetal anomalies and no abortion (unpublished observation, A. Holmäng). This dose had also been used by Götz et al. (12), who reported giving it i.p. from day 17 to 21 of pregnancy in rats, resulting in alterations in psychomotor development and behavior.

Gestation lasted for $22 \mathrm{~d}$ in all dams. Body weight and food intake of the dams were recorded throughout the pregnancy. All the dams were presented with the same amount of food, and food intake was measured the next day by subtracting the remaining uneaten food. This was calculated as food intake in grams per rat and day. Core body temperature of the dams was measured by a rectal probe $3 \mathrm{~h}$ after the IL-1 injection, as previously described (25). One IL-1 dam and one control dam did not deliver. Litters were weighed at birth and placed with their dams within each experimental group. Male and female offspring were brought up together, and each dam had equal numbers of pups $(7,8)$ to guarantee similar feeding conditions. Litters were adjusted so that they contained approximately the same ratio of male to female pups. Pups were left undisturbed until weaning at $4 \mathrm{wk}$ of age, except for the occasion when they were weighed. Offspring were killed by an overdose of anesthesia at 10 (male) or 12 (female) wk of age.

Food intake. On two different occasions, when the rat offspring were 5 and 9 wk of age, their food consumption was recorded for the whole day. All were presented with the same amount of food, and their intake was measured the next day by subtracting the remaining uneaten food. This was done for 1 wk, and food intake was calculated in grams per rat and day.
Hormone analysis. Blood was collected in heparinized microtubes and centrifuged immediately in a microcentrifuge at $4^{\circ} \mathrm{C}$. Testosterone was measured with a solid-phase RIA (CoatA-Count Total Testosterone, Diagnostic Products, Los Angeles, CA, U.S.A.), and $17 \beta$-estradiol was determined with an ultrasensitive estradiol RIA (Diagnostic Systems Laboratories, Webster, TX, U.S.A.). Progesterone was assayed with a commercially available enzyme immunoassay (progesterone ELISA; Biomar Diagnostic Systems, Marburg, Germany). Corticosterone was determined with an RIA (RSL ${ }^{125}$ I corticosterone RIA; ICN Biomedicals, Costa Mesa, CA, U.S.A.; detection level above $25 \mathrm{ng} / \mathrm{mL}$ ). Leptin was determined by an RIA (Rat Leptin RIA kit; Linco Research, St. Louis, MO, U.S.A.). Serum IGF-I was measured by a double-antibody IGF binding protein-blocked RIA (IGF-I, IGFBP blocked, Mediagnost, Tubingen, Germany). Serum osteocalcin levels were measured by an ELISA (Rat-MID osteocalcin ELISA, Osteometer BioTech A/S, Herlev, Denmark). TRAP 5b was analyzed in serum with a solid-phase immunofixed enzyme activity assay (Rat TRAP; Suomen Bioanalytiikka Oy, SBA Sciences, Oulu, Finland). A C-terminal telopeptide fragments of type I collagen cross-links were analyzed with a RatLaps kit (Osteometer Bio TechA/S).

\section{DXA}

BMC and areal BMD (BMC per square centimeter) were measured with the pDEXA Sabre and Sabre Research software (both from Norland Medical Systems Inc., Fort Atkinson, WI, U.S.A.). Ex vivo measurements of tibia and vertebra L6 were performed on excised bones placed on a 1-cm-thick Plexiglas table. All bones compared were measured in the same scan as previously described (26).

\section{PQCT}

Computed tomography was performed with the Stratec pQCT XCT Research M (software version 5.4B; Norland Medical Systems Inc.) operating at a resolution of $70 \mu \mathrm{m}$ (27).

Mid-diaphyseal pQCT scans of the tibia were performed to determine the cortical BMC, the cortical volumetric BMD, the cortical cross-sectional area, the cortical thickness, and the periosteal and endosteal circumference. The mid-diaphyseal region of the femur and tibia in rats contains mostly cortical bone (26).

Metaphyseal pQCT scans of the left tibia were performed to measure trabecular volumetric BMD. The scan was positioned in the metaphysis at a distance from the proximal growth plate corresponding to $5 \%$ of the total length of the tibia (an area containing a central portion of trabecular bone). The trabecular bone region was defined by setting an inner threshold of $45 \%$ of the total area. The interassay coefficients of variation for the pQCT measurements were less than $2 \%$.

It should be emphasized that the DXA technique gives the areal $\mathrm{BMD}$, whereas the $\mathrm{pQCT}$ gives the real, volumetric BMD. Thus, DXA gives the mineral content per area, not per volume. Therefore, a factor regulating the outer dimensions of a bone will affect the areal BMD (DXA) but not the volumetric BMD (pQCT). 


\section{HISTOMORPHOMETRIC ANALYSIS}

Histomorphometric analysis was performed on the rat distal femur of 10-wk-old male rats (Pharmatest Services Ltd., Turku, Finland). The variables were calculated from one section of each bone sample. Six fields (two rows, total area 4.6 $\mathrm{mm}^{2}$ ) were measured $0.9 \mathrm{~mm}$ above the growth plate in each section. The following variables were determined: trabecular bone volume relative to tissue volume, trabecular thickness, osteoclast surface relative to bone surface, and number of osteoclasts relative to bone surface.

\section{STATISTICAL METHODS}

Distribution of variables is given as mean \pm SEM. A Mann-Whitney nonparametric $U$ test was used for comparison between the treatment groups and the control groups. A twotailed $p$ value of $<0.05$ was considered statistically significant.

\section{RESULTS}

Dams and litters. The body weight of the dams increased throughout pregnancy, and there was no significant difference in body weight between the two groups at any time (data not shown). There was an insignificant tendency to an increase in core body temperature in the IL-1-exposed animals $\left(37.7^{\circ} \pm\right.$ $\left.0.8^{\circ} \mathrm{C}\right)$ compared with control dams $\left(37.0^{\circ} \pm 0.3^{\circ} \mathrm{C}\right)$. A significant reduction in food intake was seen in IL-1-exposed dams, on days 9, 11, 13, and 14 (Fig. 1). However, no significant difference was found in litter size for the IL-1exposed group compared with the control group [IL-1, $6.0 \pm$ 1.1 ; controls, $7.2 \pm 0.9(n=10$ in each group $)]$.

Body weights of offspring. There was no difference in body weight between the newborn pups in the IL-1-injected group and the controls [male IL-1, $6.80 \pm 0.16 \mathrm{~g}(n=15)$; controls, $6.68 \pm 0.1 \mathrm{~g}(n=22)$, female IL-1, $6.49 \pm 0.12 \mathrm{~g}(n=20)$; controls, $6.41 \pm 0.12(n=21)]$. Body weight was recorded

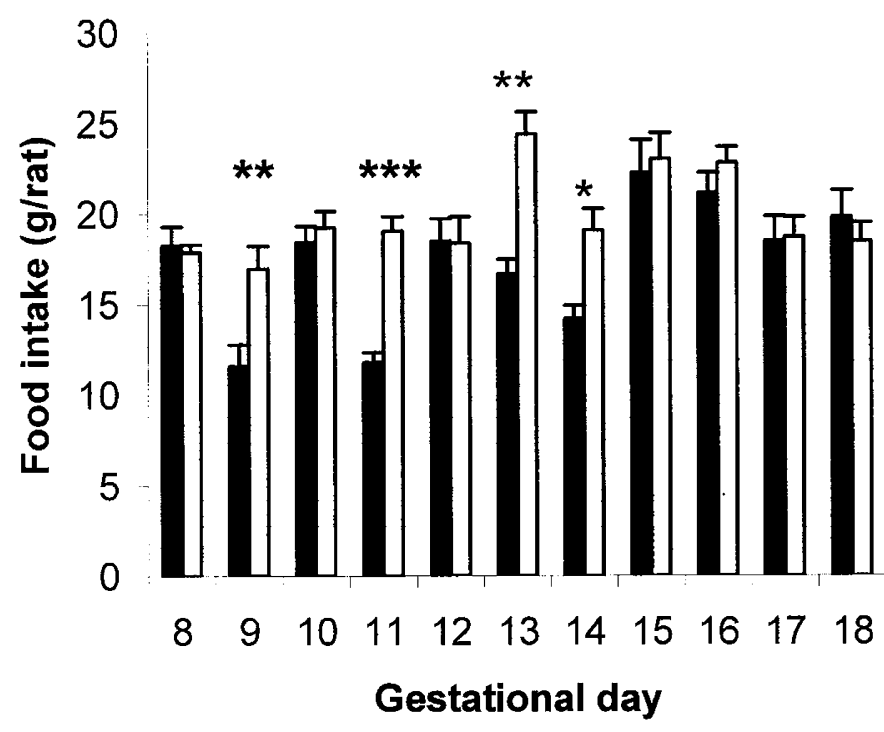

Figure 1. Food intake (g/rat and day) in IL-1-exposed dams (solid bars, $n=$ 6) and control dams (open bars, $n=6$ ) from gestational day 8 until day 18 . Values are mean \pm SEM. Data were analyzed with Mann-Whitney nonparametric $U$ test. ${ }^{*} p<0.05, * * p<0.01, * * * p<0.001$; IL-1 vs control. from week 1 to week 10 for male offspring and from week 1 to week 11 for female offspring. No significant effect on body weight was seen at any time (data not shown). Food intake was measured in control offspring and IL-1-treated offspring at 5 wk of age and between 9 and 10 wk of age. There was no difference in food intake between IL-1-treated and control offspring (data not shown).

Organ weights. The weights of different organs were measured at $12 \mathrm{wk}$ of age for female rats and at $10 \mathrm{wk}$ of age for male rats. No difference were found in the weights of muscle, adipose tissue, gonads, thymus, spleen, or heart, but the adrenals of male IL-1-treated offspring were slightly lighter than the adrenals of control offspring [IL-1, $0.20 \pm 0.01 \mathrm{~g}$; controls, $0.23 \pm 0.01 \mathrm{~g} ;(n=9-12), p<0.05]$.

Skeletal growth. The height of vertebrae L5 and L6 and the length of the tibia were measured at $10 \mathrm{wk}$ of age for male rats and at 12 wk of age for female rats (Table 1). Male IL-1treated offspring showed clearly reduced vertebral heights (Table 1). Tibial lengths were reduced in both male and female IL-1-treated offspring (Table 1).

Bone mineral status as determined by DXA. Areal BMD of the spine and tibia were examined by DXA. IL-1-treated male offspring had a reduced areal BMD in the spine but not in the tibia compared with control rats (Table 2).

Trabecular bone as determined by $p Q C T$ and histomorphometric analyses. The $\mathrm{pQCT}$ analysis was performed to investigate whether there were any specific effects on cortical or trabecular bone, which could not be separated by DXA analysis. The trabecular volumetric BMD in the proximal metaphysis of the tibia was unchanged in the IL-1-treated offspring [male IL-1, $0.269 \pm 0.009 \mathrm{mg} / \mathrm{mm}^{3}$; controls, 0.249 $\pm 0.012 \mathrm{mg} / \mathrm{mm}^{3}$, female IL- $1,0.516 \pm 0.032 \mathrm{mg} / \mathrm{mm}^{3}$; controls $0.457 \pm 0.027 \mathrm{mg} / \mathrm{mm}^{3}(n=10$ in each group)]. Histomorphometric analyses verified that the trabecular bone variables were unchanged in the IL-1-treated male offspring (Table 3).

Cortical bone as determined by pQCT. Cortical bone variables were analyzed in the mid-diaphyseal region of the tibia. Male IL-1-treated offspring showed a clear reduction in cortical BMC caused by a decreased cortical cross-sectional area although a slight increase in cortical volumetric BMD was seen. The reduced cortical cross-sectional area was the result of decreased cortical thickness (Fig. 2). Female IL-1-treated offspring showed a nonsignificant tendency for reduced amount of cortical bone (data not shown).

Serum variables. Serum levels of TRAP $5 b$ were increased in male offspring compared with females in the untreated group

Table 1. Length of tibia and height of vertebrae

\begin{tabular}{lccccc}
\hline & \multicolumn{3}{c}{ Male } & & \multicolumn{2}{c}{ Female } \\
\cline { 2 - 3 } \cline { 5 - 6 } & $\begin{array}{c}\text { Control } \\
(n=10)\end{array}$ & $\begin{array}{c}\text { IL-1 } \\
n\end{array}$ & & $\begin{array}{c}\text { Control } \\
(n=10)\end{array}$ & $\begin{array}{c}\text { IL-1 } \\
(n=10)\end{array}$ \\
\hline Vertebra L5 $(\mathrm{mm})$ & $7.37 \pm 0.15$ & $6.90 \pm 0.09^{*}$ & & $6.92 \pm 0.11$ & $6.51 \pm 0.16$ \\
Vertebra L6 (mm) & $7.40 \pm 0.07$ & $7.03 \pm 0.11^{*}$ & & $6.93 \pm 0.11$ & $6.99 \pm 0.09$ \\
Tibia $(\mathrm{mm})$ & $37.90 \pm 0.20$ & $37.10 \pm 0.20^{* *}$ & $35.20 \pm 0.20$ & $34.60 \pm 0.20^{*}$ \\
\hline
\end{tabular}

Bone measurements were made at $10 \mathrm{wk}$ of age (male) or $12 \mathrm{wk}$ of age (female). Values are given as mean \pm SEM. Data were analyzed with Mann-Whitney nonparametric $U$ test. ${ }^{*} p<0.05,{ }^{*}{ }^{*} p<0.01$; IL-1 $v s$ control. 
Table 2. DXA measurements

\begin{tabular}{|c|c|c|c|c|}
\hline & \multicolumn{2}{|c|}{ Male rats } & \multicolumn{2}{|c|}{ Female rats } \\
\hline & Control $(n=10)$ & IL-1 $(n=10)$ & Control $(n=10)$ & IL-1 $(n=10)$ \\
\hline Spine areal BMD $\left(\mathrm{g} / \mathrm{cm}^{2}\right)$ & $0.175 \pm 0.003$ & $0.164 \pm 0.002 * *$ & $0.166 \pm 0.003$ & $0.164 \pm 0.003$ \\
\hline Tibia areal BMD $\left(\mathrm{g} / \mathrm{cm}^{2}\right)$ & $0.155 \pm 0.001$ & $0.155 \pm 0.002$ & $0.156 \pm 0.002$ & $0.155 \pm 0.001$ \\
\hline
\end{tabular}

DXA was performed at $10 \mathrm{wk}$ of age for male rats and at $12 \mathrm{wk}$ of age for female rats. Values are given as mean \pm SEM. Data were analyzed with Mann-Whitney nonparametric $U$ test. ${ }^{* *} p<0.01$, IL-1 $v s$ control.

Table 3. Histomorphometric analysis

\begin{tabular}{lcccc}
\hline & BV/TV $(\%)$ & Tb Th $(\mu \mathrm{m})$ & OcS/BS $(\%)$ & $\begin{array}{c}\text { No. Oc/BS } \\
(/ \mathrm{mm})\end{array}$ \\
\hline Control $(n=5)$ & $19.9 \pm 1.2$ & $48.2 \pm 4.5$ & $13.8 \pm 1.4$ & $3.9 \pm 0.3$ \\
IL-1 $(n=6)$ & $18.9 \pm 2.0$ & $45.2 \pm 2.8$ & $10.6 \pm 1.4$ & $3.2 \pm 0.4$ \\
\hline
\end{tabular}

Values are given as mean \pm SEM. Data were analyzed with Mann-Whitney nonparametric $U$ test.

trabecular bone volume/tissue volume (BV/TV), trabecular thickness (TB.Th), osteoclast surface/bone surface (Oc.S./B.S) and number of osteoclasts/bone surface (N.Oc/B.S.).

Abbreviations used: $\mathrm{BV} / \mathrm{TV}$, trabecular bone volume relative to tissue volume; TB Th, trabecular thickness; OcS/BS, osteoclast surface relative to bone surface; Oc/BS, osteoclasts relative to bone surface. $(p<0.01)$. After prenatal exposure to IL-1 this sex difference in TRAP 5 b levels disappeared (Table 4). C-terminal type I collagen levels were reduced, whereas testosterone levels were increased in female IL-1-treated rats compared with controls. Serum levels of IGF-I, corticosterone, leptin, progesterone, estradiol, and osteocalcin were unchanged in IL-1-treated offspring compared with controls in both males and females (Table 4).

\section{DISCUSSION}

The programming hypothesis, whereby events early in life or during specific fetal periods have long-lasting effects later in
A) Cortical content

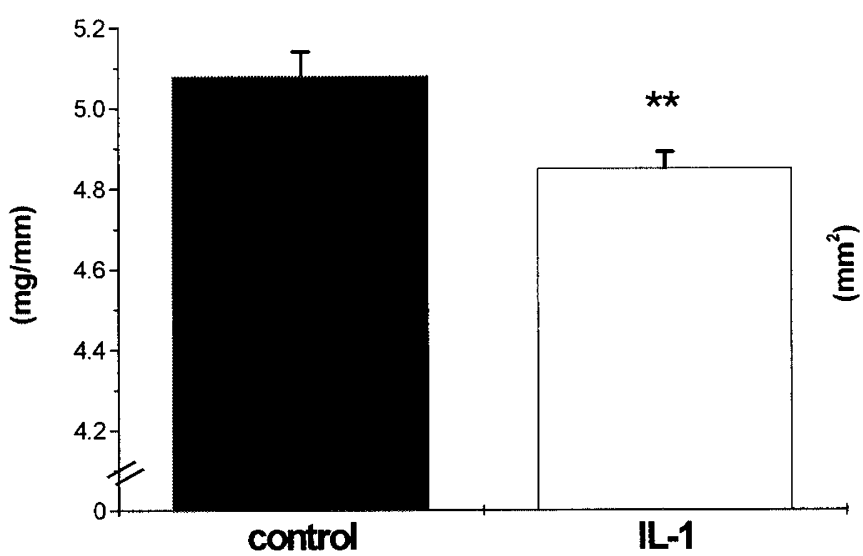

C) Cortical density

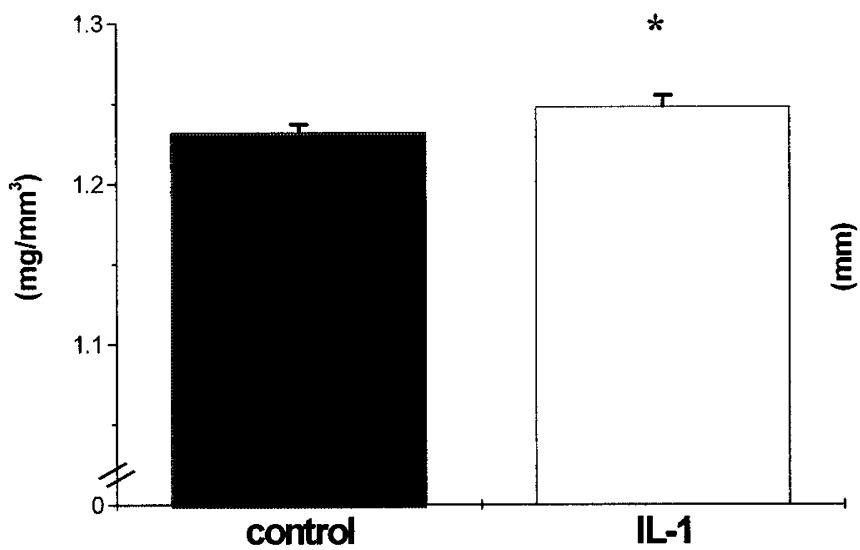

B) Cortical area

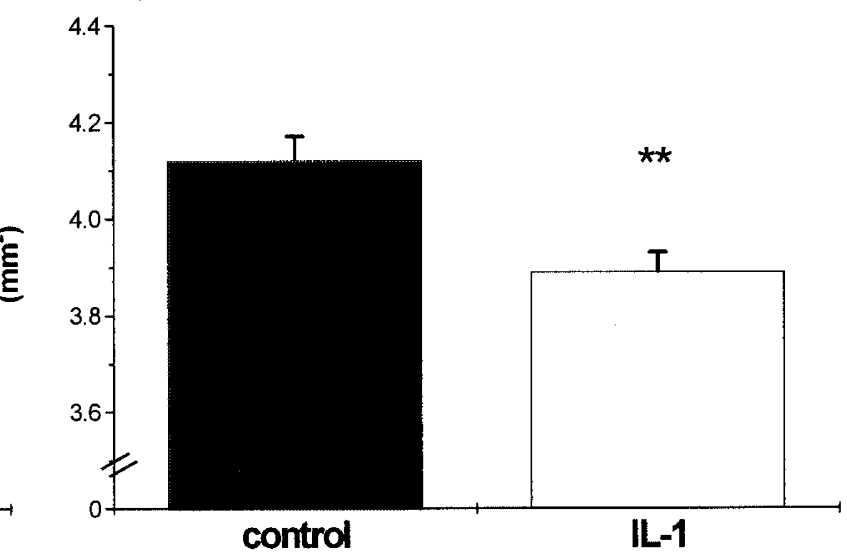

D) Cortical thickness

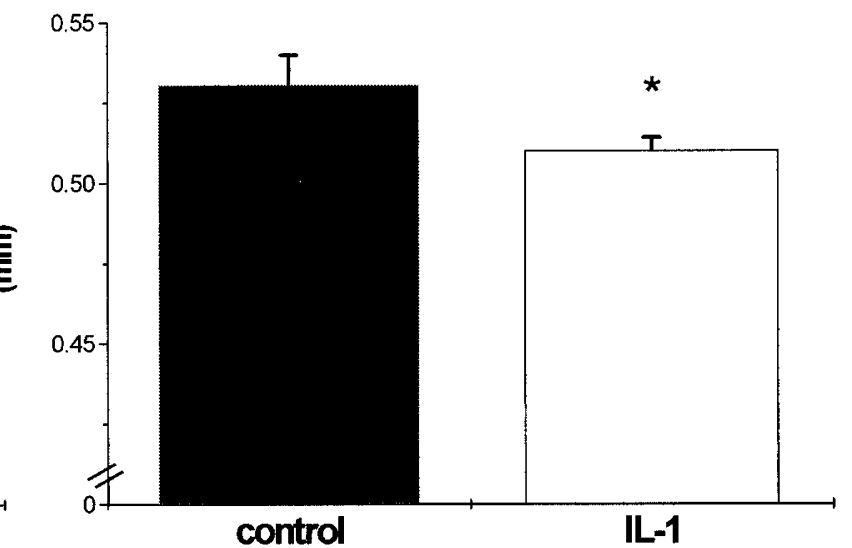

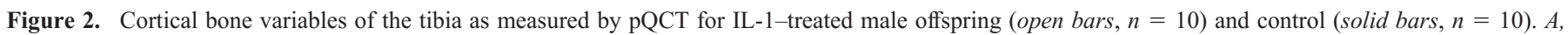

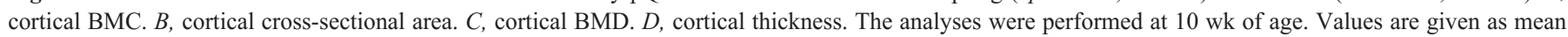
\pm SEM. Data were analyzed with Mann-Whitney nonparametric $U$ test. ${ }^{*} p<0.05$, $* * p<0.01$; IL-1 vs controls. 
Table 4. Serum variables

\begin{tabular}{|c|c|c|c|c|}
\hline & \multicolumn{2}{|c|}{ Male } & \multicolumn{2}{|c|}{ Female } \\
\hline & Control & IL-1 & Control & IL-1 \\
\hline Osteocalcin (ng/mL) & $222 \pm 11$ & $228 \pm 9$ & $222 \pm 18$ & $192 \pm 12$ \\
\hline C-terminal type I collagen $(\mathrm{ng} / \mathrm{mL})$ & $55.6 \pm 4.0$ & $55.7 \pm 4.8$ & $74.6 \pm 12.2$ & $48.3 \pm 2.7^{* *}$ \\
\hline IGF-I (ng/mL) & $603 \pm 50$ & $735 \pm 67$ & $832 \pm 70$ & $719 \pm 69$ \\
\hline Corticosterone (ng/mL) & $287 \pm 23$ & $316 \pm 51$ & $374 \pm 48$ & $287 \pm 51$ \\
\hline Progesterone (nM) & $3.45 \pm 0.85$ & $6.46 \pm 1.39$ & $25.23 \pm 3.7$ & $25.9 \pm 3.7$ \\
\hline Estradiol $(\mathrm{pM})$ & Not detectable & Not detectable & $15.8 \pm 1.9$ & $14.2 \pm 1.2$ \\
\hline
\end{tabular}

Biochemical serum variables measured between 5 and $12 \mathrm{wk}$ of age for male and female rats $(n=9-12)$. Values are given as mean \pm SEM. Data were analyzed with Mann-Whitney nonparametric $U$ test. ${ }^{*} p<0.05,{ }^{* *} p<0.01$; IL-1 vs control.

life, is supported by human epidemiologic data and animal models. Several studies have demonstrated that changes in the nutritional, metabolic, and hormonal environment during both prenatal and postnatal periods of life may have profound effects on body composition, glucose tolerance, blood pressure, and cardiovascular diseases $(2,3,28,29)$. A recent clinical study suggests that a low birth weight is associated with decreased bone and muscle mass in adults, indicating that the risk of osteoporosis in later life might be programmed by genetic or environmental influences during gestation (6). The notion that skeletal growth may be programmed during intrauterine or early postnatal life is supported by a study by Cooper et al. (30), demonstrating a relationship between adult bone mass and weight at $1 \mathrm{y}$ of age.

IL-1 levels might be increased in pregnant women as well as in newborns as a result of, for instance, infections and inflammatory diseases. Previous studies regarding prenatal exposure to IL-1 have focused on alterations in psychomotor development, behavior, and the neuroendocrine system $(12,13)$. The aim of the present study was to investigate whether prenatal IL-1 exposure affects skeletal growth or adult bone metabolism in rat offspring.

We demonstrate that prenatal IL-1 exposure results in decreased axial as well as appendicular skeletal growth. One possible explanation for the reduced skeletal growth could be that the food intake of dams was reduced after each IL-1 injection. It is well known that low birth weight is associated with insulin resistance in children and adolescents $(4,5)$. Furthermore, intrauterine exposure to a maternal low-protein diet has recently been shown to reduce adult bone mass and alter growth plate morphology in rats (31). However, as the reduction in food intake in the dams that occurred the day after the injection affected neither the total body weight of the dam nor the birth weight of the IL-1-exposed offspring, it is unlikely that the decreased food intake is involved in the disturbed skeletal growth in the offspring. To definitively rule out differences in food intake of the dams as being involved in mechanism behind the skeletal phenotype in the offspring, additional studies including pair feeding of untreated animals are required. Interestingly, the weights of several different organs and tissues, including muscles, fat depots, gonads, thymus, spleen, and heart, were unchanged in the IL-1-treated offspring, indicating that the skeletal effect was specific and did not just reflect a general growth disturbance.
The weight of the adrenals was, however, decreased in male offspring. Similarly, in a previous study by Götz et al. (12), it was demonstrated that exposure to IL-1 late in pregnancy (days 17-21) resulted in decreased adrenal weight in the offspring. Furthermore, both in the present study and in the study by Götz et al. (12), it was found that serum levels of androgens were increased in IL-1-treated female offspring.

In this study we found evidence that the skeletal tissue is another target for the programming theory. DXA measurements demonstrated that areal BMD was decreased in the spine. The pQCT technique and histomorphometry were used to separate the effects on cortical bone and trabecular bone. Both the pQCT technique and histomorphometry demonstrated that trabecular bone was unaffected in the IL-1-treated offspring. However, male IL-1-treated offspring showed a clear reduction in cortical BMC, caused by a decreased cortical cross-sectional area. The reduced cortical cross-sectional area was the result of decreased cortical thickness. Interestingly, serum levels of the osteoclast bone marker TRAP 5b were decreased in male and increased in female IL-1-treated offspring. The mechanism behind this effect remains to be elucidated.

In the present study a clear effect was seen on the axial skeletal (vertebrae) growth whereas only a modest effect was seen on the appendicular skeletal (tibia) growth. There are a limited number of previous reports regarding fetal programming of the skeleton $(32,33)$. However, the effect on the appendicular skeletal growth in the present study was of the same magnitude as previously reported in studies using prenatal exposure with leptin and dexamethasone, and the effect on the axial skeletal growth was of the same magnitude as prenatal leptin exposure but more pronounced than for prenatal dexamethasone exposure $(32,33)$.

Our study clearly demonstrates that exposure to IL-1 results in decreased skeletal growth and affects cortical bone variables in rat offspring. However, the mechanism behind this effect is unclear and might include both central and peripheral effects. One possible mechanism is that IL-1 might exert a direct central effect on the brain, supported by the fact that the IL-1 treatment in the present study corresponds to an early period when fetal brain development occurs in the rat (34). It is well known that IL-1 increases glucocorticoid secretion by enhancing synthesis and release of corticotropin-releasing hormone and ACTH (35). We have previously demonstrated that treat- 
ment with dexamethasone results in disturbed skeletal growth in the offspring (32). A disturbed HPA axis in the treated offspring is supported by the fact that the weight of the adrenal gland was decreased in male offspring. However, basal serum levels of corticosterone were unchanged. Dysregulation of the HPA axis, however, cannot be excluded, as a reduced corticosterone response to stress has been seen after postnatal IL-1 administration (13).

IL-1 exerts direct effects on skeletal cells $(19,20)$. Thus the effect of IL-1 on skeletal programming might be a direct effect on skeletal cells, including chondrocytes, osteoblasts, and osteoclasts. An effect at the cellular level has recently been reported by Oreffo et al. (36). They found reduced osteoblast activity and affected bone marrow stromal cells in offspring from mothers on a low-protein diet. A third pathway by which IL-1 might influence skeletal programming in the offspring is an indirect effect via the placenta or via hormones and growth factors in the pregnant dam. A limitation with the present study is that the exact mechanism for the described skeletal effects is not identified, and therefore future additional mechanistic studies are required.

\section{CONCLUSIONS}

Our results demonstrate that prenatal exposure of IL-1 can induce specific programming of skeletal tissue. In conclusion, prenatal IL-1 exposure results in decreased skeletal growth and reduced amount of cortical bone but unchanged trabecular $\mathrm{BMD}$ in rat offspring.

Acknowledgments. The authors thank Britt-Mari Larsson, Anette Hansevi, and Maud Petterson for providing laboratory assistance. We also thank Dr. Jovanna Dahlgren for stimulating discussions.

\section{REFERENCES}

1. Barker DJP, Hales CN, Fall CHD, Osmond C, Phipps K, Clark PM 1993 Type 2 (non-insulin-dependent) diabetes mellitus, hypertension and hyperlipidaemia (syndrome X): relation to reduced fetal growth. Diabetologia 36:62-67

2. Benediktsson R, Lindsay R, Noble J, Seckl JR, Edwards CRW 1993 Glucocorticoid exposure in utero: a new model for adult hypertension. Lancet 341:339-341

3. Lucas A 1991 Programming by early nutrition in man. In: Bock GR, Whelan J (eds) The Childhood Environment and Adult Disease. John Wiley and Sons, Chichester, pp $156: 38-50$

4. Hofman PL, Cutfield WS, Robinson EM, Bergman RN, Menon RK, Sperling MA, Gluckman PD 1997 Insulin resistance in short children with intrauterine growth retardation. J Clin Endocrinol Metab 82:402-406

5. Ornoy A, Altshuler G 1976 Maternal endotoxemia, fetal anomalies, and central nervous system damage: a rat model of a human problem. Am J Obstet Gynecol 124:196-204

6. Gale CR, Martyn CN, Kellingray S, Eastell R, Cooper C 2001 Intrauterine programming of adult body composition. J Clin Endocrinol Metab 86:267-272

7. Dinarello C 1991 Interleukin-1 and interleukin-1 antagonism. Blood 77:1627-1652
8. Dollner H, Vatten L, Linnebo I, Zanussi GF, Laerdal A, Austgulen R 2001 Inflammatory mediators in umbilical plasma from neonates who develop early-onset sepsis. Biol Neonate 80:41-47

9. Hermus ARMM, Sweep CGJ 1990 Cytokines and the hypothalamic-pituitary-adrenal axis. J Steroid Biochem Mol Biol 37:867-871

10. Johnson RW 1997 Inhibition of growth by pro-inflammatory cytokines: an integrated view. J Anim Sci 75:1244-1255

11. Turnbull AV, Rivier CL 1999 Regulation of the hypothalamic-pituitary-adrenal axis by cytokines: actions and mechanisms of action. Physiol Rev 79:1-71

12. Götz FG, Dörner U, Malz W, Rohde F, Stahl I, Poppe M, Schulze A, Plagemann A 1993 Short- and long-term effects of perinatal interleukin- $1 \beta$ application in rats. Neuroendocrinology 58:344-351

13. Plagemann A, Staudt A, Götz F, Malz U, Rohde W, Rake A, Dorner G 1998 Long-term effects of early postnatally administered interleukin-1 on the hypothalamic-pituitary-adrenal (HPA) axis in rats. Endocr Regul 32:77-85

14. Gowen M, Wood DD, Ihrie EJ, McGuire MKB, Russell RGG 1983 An interleukin1-like factor stimulates bone resorption in vitro. Nature 306:378-380

15. Udagawa N 2002 Mechanisms involved in bone resorption. Biogerontology 3:79-83

16. Lorenzo J 2000 Interactions between immune and bone cells: new insights with many remaining questions. J Clin Invest 106:749-752

17. Kon T, Cho T-J, Aizawa T, Yamazaki M, Nooh N, Graves D, Gerstenfeld LC, Einhorn TA 2001 Expression of osteoprotegerin, receptor activator of NF- $\kappa$ B ligand (osteoprotegerin ligand) and related proinflammatory cytokines during fracture healing. J Bone Miner Res 16:1004-1014

18. Muller B 2002 Cytokine imbalance in non-immunological chronic disease. Cytokine 21:334-339

19. Roodman GD 2001 Biology of osteoclast activation in cancer. J Clin Oncol 19:35623571

20. Roux S, Orcel P 2000 Bone loss-factors that regulate osteoclast differentiation: an update. Arthritis Res 2:451-456

21. Keeting PE, Rifas L, Harris SA, Colvard DS, Spelsberg TC, Peck WA, Riggs BL 1991 Evidence for interleukin-1B production by cultured normal human osteoblastlike cells. J Bone Miner Res 6:827-833

22. Swolin-Eide D, Ohlsson C 1998 Effects of cortisol on the expression of interleukin-6 and interleukin-1 $\beta$ in human osteoblast-like cells. J Endocrinol 156:107-114

23. Frost A, Jonsson KB, Nilsson O, Ljunggren Ö 1997 Inflammatory cytokines regulate proliferation of cultured human osteoblasts. Acta Orthop Scand 68:91-96

24. Uehara A, Gottschall PE, Dahl RR, Arimura A 1987 Interleukin-1 stimulates ACTH release by an indirect action which requires endogenous corticotropin releasing factor. Endocrinology 121:1580-1582

25. Luheshi GN, Bluthe RM, Rushforth D, Mulcahy N, Konsman JP, Goldbach M, Dantzer R 2000 Vagotomy attenuates the behavioural but not the pyrogenic effect of interleukin-1 in rats. Auton Neurosci 85:127-132

26. Windahl SH, Vidal O, Andersson G, Gustafsson JA, Ohlsson C 1999 Increased cortical bone mineral content but unchanged trabecular bone density in female ER beta (-/-) mice. J Clin Invest 104:895-901

27. Vidal O, Lindberg MK, Hollberg K, Baylink DJ, Andersson G, Lubahn DB, Mohan S, Gustafsson JA, Ohlsson C 2000 Estrogen receptor specificity in the regulation of skeletal growth and maturation in male mice. Proc Natl Acad Sci USA 97:5474-5479

28. Holmäng A 2001 Perinatal origin of adult disease. Scand Cardiovasc J 35:178-185

29. Barker DJP 2002 Fetal programming of coronary heart disease. Trends Endocrinol Metab 13:364-368

30. Cooper C, Fall C, Egger P, Hobbs R, Eastell R, Barker D 1997 Growth in infancy and bone mass in later life. Ann Rheum Dis 56:17-21

31. Mehta G, Roach HI, Langley-Evans S, Taylor P, Reading I, Oreffo RO, Aihie-Sayer A, Clarke NM, Cooper C 2002 Intrauterine exposure to a maternal low protein diet reduces adult bone mass and alters growth plate morphology in rats. Calcif Tissue Int 71:493-498

32. Swolin-Eide D, Dahlgren J, Nilsson C, Albertsson Wikland K, Holmäng A, Ohlsson C 2002 Affected skeletal growth but normal bone mineralization in rat offspring after prenatal dexamethasone exposure. J Endocrinol 174:411-418

33. Nilsson C, Swolin-Eide D, Ohlsson C, Eriksson E, Ho H-P, Björntorp P, Holmäng A 2003 Reductions in adipose tissue and skeletal growth in rat adult offspring after prenatal leptin exposure. J Endocrinol 176:13-21

34. Paxinos G, Törk I, Tecott LH, Valentino KL 1991 Atlas of the Developing Rat Brain Academic Press, London

35. Angeli A, Masera RG, Sartori ML, Fortunati N, Racca S, Dovio A, Staurenghi A, Frairia R 1999 Modulation by cytokines of glucocorticoid action. Ann NY Acad Sci $876: 210-220$

36. Oreffo ROC, Lashbrooke B, Roach HI, Clarke NMP, Cooper C 2003 Maternal protein deficiency affects mesenchymal stem cell activity in the developing offspring. Bone 33:100-107 